\title{
Antimicrobial resistance and genetic relationships of enterococci from siblings and non-siblings Heliconius erato phyllis caterpillars
}

\author{
Rosana Huff ${ }^{1}$, Rebeca Inhoque Pereira ${ }^{2}$, Caroline Pissetti ${ }^{3}$, Aldo Mellender de Araújo ${ }^{4}$, Pedro Alves d'Azevedo $^{2}$, \\ Jeverson Frazzon ${ }^{5}$, Ana Paula Guedes Frazzon ${ }^{\text {Corresp. } 1}$ \\ 1 Institute of Basic Health Sciences, Department of Microbiology, Immunology and Parasitology, Federal University of Rio Grande do Sul, Porto Alegre, Rio \\ Grande do Sul, Brazil \\ 2 Basic Health Sciences, Department of Microbiology, Health Sciences Federal University, Porto Alegre, Rio Grande do Sul, Brazil \\ 3 Department of Veterinary Preventive Medicine, Federal University of Rio Grande do Sul, Porto Alegre, Rio Grande do Sul, Brazil \\ Institute of Biosciences, Genetic Department, Federal University of Rio Grande do Sul, Porto Alegre, Rio Grande do Sul, Brazil \\ 5 Food Science Institute, Federal University of Rio Grande do Sul, Porto Alegre, Rio Grande do Sul, Brazil \\ Corresponding Author: Ana Paula Guedes Frazzon \\ Email address: ana.frazzon@ufrgs.br
}

Background: Studies evaluating bacteria in insects can provide information about host-microorganism-environment interactions. The gut microbial community has a profound effect on different physiological functions of insects. Enterococcus spp. are part of the gut community in humans and other animals, as well as in insects. The presence and antimicrobial resistance profileof enterococci are well studied in different animals; however, data for Heliconius erato phyllis (Lepidoptera: Nymphalidae) do not yet exist. Therefore, the aims of this study were to evaluate the distribution of enterococcal species, their antimicrobial resistance profile and virulence genes, and the genetic relationships betweenenterococci isolated from fecal samples from sibling and non-sibling $\mathrm{H}$. erato phyllis caterpillars collected from different sites in South Brazil.

Methods: Three $H$. erato phyllis females were captured (two from a forest fragment and one from an urban area), and kept individually in open-air insectaries. Eggs were collected and caterpillars (siblings and non-siblings) were fed daily with Passiflora suberosa leaves. Fecal samples $(n=12)$ were collected from fifth-instar caterpillars, inoculated in selective medium, and 15 bacterial colonies were randomly selected from each sample. Enterococci were identified by PCR and MALDI-TOF, analyzed by disk diffusion antimicrobial susceptibility tests, and screened for resistance and virulence genes by PCR. The genetic relationships between the strains were determined using pulsed-field gel electrophoresis (PFGE).

Results: A total of 178 enterococci strains were identified: E. casseliflavus (74.15\%; $n=132), E$. mundtii (21.34\%; $n=38)$, E. faecalis (1.12\%; $n=2)$ and Enterococcus sp. $(3.37 \% ; n=6)$. High rates of resistance to rifampicin (56\%) and erythromycin (31\%) were observed; $120(67.41 \%)$ of the isolates showed resistance to at least one antibiotic and six (3.37\%) were multidrug-resistant.None of the erythromycin-resistant strains was positive for the erm(B) and $\mathrm{msrC}$ genes. The virulence genes esp, ace, and gelE were observed in 35\%,7\%, and 1\% of the strains, respectively. PFGE separated the enterococci into 22 patterns, four being composed of strains from sibling caterpillars.

Conclusion: Enterococcus casseliflavus was the dominant species in fecal samples of fifth-instar caterpillars. Resistant enterococci strains may be related to environmental pollution or the resistome. The PFGE analysis showed genetic relationships between some strains, suggesting that the enterococci

Peerf reviewing PDF | (2019:09:41227:1:1:NEW 18 Dec 2019) 
isolated from fecal samples of the sibling caterpillars might have come from common sources, e.g., via diet (herbivory) and/or vertical transmission (through the egg surface). Further studies will be conducted to better understand the role of Enterococcus in the microbial community of the gastrointestinal tract of these insects, and the mechanisms involved in acquisition and maintenance of enterococci. 


\section{Antimicrobial resistance and genetic relationships of 2 enterococci from siblings and non-siblings Heliconius 3 erato phyllis caterpillars}

4

5

Rosana Huff ${ }^{1}$, Rebeca Inhoque Pereira ${ }^{2}$, Caroline Pissetti ${ }^{3}$, Aldo Mellender de Araújo ${ }^{4}$, Pedro Alves d'Azevedo 2 , Jeverson Frazzon ${ }^{5}$, Ana Paula Guedes Frazzon ${ }^{1 \# .}$

1. Institute of Basic Health Sciences, Department of Microbiology, Immunology and Parasitology, Federal University of Rio Grande do Sul, Porto Alegre, RS, Brazil.

2. Basic Health Sciences, Department of Microbiology, Porto Alegre. Health Sciences Federal University, Porto Alegre, RS, Brazil.

3. Department of Veterinary Preventive Medicine, Federal University of Rio Grande do Sul, Porto Alegre, RS, Brazil.

4. Institute of Biosciences, Genetic Department, Federal University of Rio Grande do Sul, Porto Alegre, RS, Brazil.

5. Food Science Institute, Federal University of Rio Grande do Sul, Porto Alegre, RS, Brazil.

Corresponding Author:

Dra. Ana Paula Guedes Frazzon ${ }^{1}$

Institute of Basic Health Sciences, Department of Microbiology, Immunology and Parasitology, Federal University of Rio Grande do Sul, Rua Sarmento Leite, 500, ZIP CODE: 90500-170, Porto Alegre, RS, Brazil.

Fone: +555133084505 .

Email address: ana.frazzon@ufrgs.br

\section{Abstract}

Background: Studies evaluating bacteria in insects can provide information about hostmicroorganism-environment interactions. The gut microbial community has a profound effect on different physiological functions of insects. Enterococcus spp. are part of the gut community in humans and other animals, as well as in insects. The presence and antimicrobial resistance profile of enterococci are well studied in different animals; however, data for Heliconius erato phyllis (Lepidoptera: Nymphalidae) do not yet exist. Therefore, the aims of this study were to evaluate the distribution of enterococcal species, their antimicrobial resistance profile and virulence genes, and the genetic relationships between enterococci isolated from fecal samples from sibling and non-sibling $H$. erato phyllis caterpillars collected from different sites in South Brazil.

Methods: Three H. erato phyllis females were captured (two from a forest fragment and one from an urban area), and kept individually in open-air insectaries. Eggs were collected and 
39

40

41

42

43

44

45

46

47

48

49

50

51

52

53

54

55

56

57

58

59

60

61

62

63

64

65

66

67

68

69

70

71

72

73

74

75

76

77

caterpillars (siblings and non-siblings) were fed daily with Passiflora suberosa leaves. Fecal samples $(\mathrm{n}=12)$ were collected from fifth-instar caterpillars, inoculated in selective medium, and 15 bacterial colonies were randomly selected from each sample. Enterococci were identified by PCR and MALDI-TOF, analyzed by disk diffusion antimicrobial susceptibility tests, and screened for resistance and virulence genes by PCR. The genetic relationships between the strains were determined using pulsed-field gel electrophoresis (PFGE).

Results: A total of 178 enterococci strains were identified: E. casseliflavus $(74.15 \% ; \mathrm{n}=132), E$. mundtii $(21.34 \% ; \mathrm{n}=38)$, E. faecalis $(1.12 \% ; \mathrm{n}=2)$ and Enterococcus sp. $(3.37 \% ; \mathrm{n}=6)$. High rates of resistance to rifampicin (56\%) and erythromycin (31\%) were observed; $120(67.41 \%)$ of the isolates showed resistance to at least one antibiotic and six $(3.37 \%)$ were multidrugresistant. None of the erythromycin-resistant strains was positive for the $\operatorname{erm}(\mathrm{B})$ and $m s r \mathrm{C}$ genes. The virulence genes esp, ace, and gelE were observed in $35 \%, 7 \%$, and $1 \%$ of the strains, respectively. PFGE separated the enterococci into 22 patterns, four being composed of strains from sibling caterpillars.

Conclusion: Enterococcus casseliflavus was the dominant species in fecal samples of fifth-instar caterpillars. Resistant enterococci strains may be related to environmental pollution or the resistome. The PFGE analysis showed genetic relationships between some strains, suggesting that the enterococci isolated from fecal samples of the sibling caterpillars might have come from common sources, e.g., via diet (herbivory) and/or vertical transmission (through the egg surface). Further studies will be conducted to better understand the role of Enterococcus in the microbial community of the gastrointestinal tract of these insects, and the mechanisms involved in acquisition and maintenance of enterococci.

\section{Introduction}

Heliconius (Lepidoptera: Nymphalidae) represents a widespread genus of butterflies distributed throughout tropical and subtropical regions, from South America to the southern United States (Brown, 1981; Merril et al., 2015). Adults feed on pollen as well as nectar (Gilbert, 1972; Merril et al., 2015), and this food supply provides a better use of resources and a reduction in competition since the same flower can provide nutrients for both Heliconius and other butterflies that exclusively use nectar as food. This diet is rich in amino acids that allow adult females to oviposit on a daily basis during their lives (Gilbert, 1972). Heliconius erato phyllis is a subspecies commonly found in forests and urban environments from northeastern Brazil to northern Argentina. Adult females are monandrous, i.e., they mate only once, and lay their eggs individually in the apical meristem of a host plant, to minimize potential cannibalization of eggs by first-instar caterpillars (De Nardin et al., 2016). Several species of passionflower vines, including Passiflora suberosa, P. misera and P. capsularis, host plants for oviposition and feeding of caterpillars.These Passiflora species, commonly found in Southern Brazil where this study was conducted, have cyanogenic glycosides, which are assimilated by the caterpillars to make them unpalatable to potential predators. However, adults of $H$. erato phyllis

Peer) reviewing PDF | (2019:09:41227:1:1:NEW 18 Dec 2019) 
are also able to synthesize cyanogenic glycosides and transfer them to their eggs (Hay-Roe \& Nation, 2007).

It has been recognized for a long time that microorganisms play key roles in various physiological functions of animal hosts. The gut microbial community promotes an especially diverse range of benefits for insects, e.g., by improving nutrition via synthesis of vitamins and/or establishment of metabolic pathways, actively participating in degradation of xenobiotic compounds, and contributing to the defense against invading pathogens and immune system modulation (Douglas, 2015; Shao et al., 2017). The presence of microorganisms in the gastrointestinal (GI) tract of insects can be explained by environmental bacteria ingested with food and/or acquired by maternal transfer (Engel \& Moran, 2013). A growing number of studies have addressed the importance of the microbiota in the GI tract of insects (Engel \& Moran, 2013; Chen et al., 2016; Douglas, 2018), and Enterococcus is one of the most frequent bacterial genera present in the gut microbiota at different life stages of Lepidoptera (Brinkmann, Matens \& Tebbe, 2008; Chen et al., 2016; Snyman et al., 2016; van Shooten et al., 2018; Allonsius et al., 2019).

The Enterococcus genus is often found in the GI tract of humans and animals, as well as in the guts of insects (Shao et al., 2017). Hammer et al. (2014) reported that Enterococcus was the most abundant genus found in immature stages and adults of $H$. erato from Panama. Furthermore, it has also been reported in insects of other orders, such as Coleoptera (Kim et al., 2017), Hymenoptera (Audisio et al., 2011), and Diptera (Ghosh et al., 2014). A characteristic of this genus is its intrinsic resistance to several antimicrobial agents and a great ability to transfer and acquire resistant genes (Hollenbeck \& Rice, 2012). Despite the environmental resistome, the intense use of antimicrobials and anthropogenic activities, such as animal husbandry, agronomic practices, and wastewater treatment, play an important role in the emergence and spread of resistant-enterococci and/or antibiotic resistance genes in the environment, especially in soil, water, wastewater, and food (Gothwal \& Shashidhar, 2014; Singer et al., 2016).

Antimicrobial resistance is one of the most serious public health problems, because of the spread of resistant bacteria leading to persistent infections, which are difficult to treat, and contamination of natural environments (Watkins \& Bonomo, 2016; Ferri et al., 2017; Aslam et al., 2018). Insects have a wide distribution and can move freely between different environments; they may play an important role as reservoirs of drug-resistant strains and as their disseminators between animals and humans, especially when in contact with organic waste, livestock and their surrounding environment, and hospital facilities (Zurek \& Ghosh, 2014; Mohammed et al., 2016; Schaumburg et al., 2016; Zhang et al., 2017; Onwugamba et al., 2018). In relation to insects caring antibiotic-resistant bacterial strains, studies have identified flies (Ahmad et al., 2011; Usui et al., 2015; Mohammed et al., 2016; Schaumburg et al., 2016; Zhang et al., 2017; Onwugamba et al., 2018) and cockroaches (Ahmad et al., 2011; Pai, 2013; Moges et al., 2016) as hosts of extended-spectrum beta-lactamase- and carbapenemase-producing Enterobacteriaceae, vancomycin-resistant E. faecium (VRE), and methicillin-resistant Staphylococcus aureus (MRSA). Insects collected from food establishments and in association 
118 with stored products were also found to be colonized by antimicrobial-resistant 119 bacteria (Macovei \& Zurek, 2006; Channaiah et al., 2010; Mohammed et al., 2016). Despite

120

121

122

123

124

125

126

127

128

129

130

131

132

133

134

135

136

137

138

139

140

141

142

143

144

145

146

147

148

149

150

151

152

153

154

155

156

157 their importance, few studies have addressed the concern of insects carrying resistant enterococci (Allen et al., 2009; Channaiah et al., 2010; Ahmad et al., 2011; Lowe \& Romney, 2011).

As previously mentioned, the Enterococcus genus is often found in the GI tract in Lepidoptera (Hammer, McMillan \& Fierer, 2014; Chen et al., 2016; Snyman et al., 2016; van Shooten et al., 2018; Allonsius et al., 2019), and it may play a fundamental role in the development and regulation of bacterial communities in these insects (Chen et al., 2016; Shao et al., 2017). The identification of enterococcal strains and their resistance profile in insects is an important aspect that must be addressed for host-microorganism-environment interactions. To our knowledge, there have been no studies to date evaluating enterococci in $H$. erato phyllis. The aims of our research were to analyze enterococcal species distribution, their antimicrobial resistance profile and virulence genes, and the genetic relationships between enterococci isolated from fecal samples from sibling and non-sibling $H$. erato phyllis caterpillars collected from different sites in South Brazil.

\section{Materials \& Methods}

\section{Sample collection}

The fecal samples used in the present study were collected from fifth instar caterpillars. The caterpillars were sourced from three different populations of Heliconius erato phyllis butterflies and consisted of sibling from the same female. The H. erato phyllis females (HE) were captured with entomological nets in Rio Grande do Sul, South Brazil. The first female (HEAB2) was collected in a forest fragment located in Águas Belas Agronomical Station $\left(30^{\circ}\right.$ $02^{\prime} 18.1^{\prime \prime ~ S} ; 51^{\circ} 01^{\prime} 23.0^{\prime \prime} \mathrm{W}$ ), the second female (HEV2) from a population in an intense urban area in Viamão ( $30^{\circ} 09^{\prime} 40.5^{\prime \prime} \mathrm{S} ; 50^{\circ} 55^{\prime} 01.5^{\prime \prime} \mathrm{W}$ ) and the third female (HES2) in a forest fragment located in São Francisco de Paula (29 26' 34.1" S; 50 36' 48.8" W).

Butterflies were kept individually in open-air insectaries with dimensions of $2.3 \mathrm{~m}$ x $3 \mathrm{~m}$ x $3 \mathrm{~m}$ (width, length, height) approximately. Insectaries had many plants for simulation of natural conditions, including $P$. suberosa, used by females for oviposition. The butterflies were fed daily with a mixture containing water, honey and pollen.

A total of 12 eggs were collected (five from HEAB2, five from HEV2 and two from HES2) with the assistance of a paintbrush. The eggs were transported to the laboratory, and caterpillars were grown individually in cylindrical plastic pots. Immatures were fed exclusively with $P$. suberosa leaves (Fig. 1). Fecal samples were collected from each caterpillar individually after $48 \mathrm{~h}$ of molting to the fifth instar $(\mathrm{n}=12)$, with the aid of a disposable plastic spoon, stored in $1.5 \mathrm{~mL}$ microtubes and maintained at $-80^{\circ} \mathrm{C}$ until processing. The oviposition dates are shown in Table S1.

This study was carried out in accordance with the recommendations of Chico Mendes Institute for Biodiversity Conservation (ICMBio). The protocol was approved by Information Authorization System in Biodiversity (SISBIO) number 33404-1. This study has the Council for 
158 the Management of Genetic Patrimony - CGEN - under the Ministry of Environment number 159 A720680.

\section{Isolation and identification of Enterococci}

161

162

163

164

165

166

167

168

169

170

171

172

173

174

175

176

177

178

179

180

181

182

183

184

185

186

187

188

189

190

191

192

193

194

195

196

Isolation and identification of enterococci were performed as previously described in Santestevan et al. (2015), with modifications. One milligram of fecal sample was transferred to $10 \mathrm{~mL}$ of saline $0.85 \%$ and incubated at $37^{\circ} \mathrm{C}$ for $24 \mathrm{~h}$. One $\mathrm{mL}$ was inoculated in $9 \mathrm{~mL}$ of Azide Dextrose Broth selective medium (Himedia, Mumbai, India) and incubated for $24 \mathrm{~h}$ at $37^{\circ} \mathrm{C}$. Aliquots $(1 \mathrm{~mL})$ were placed in $9 \mathrm{~mL}$ of saline $0.85 \%$, and initial samples were further diluted 10 -fold. From dilution $10^{-5}$ and $10^{-6}, 100 \mu \mathrm{L}$ was inoculated in brain heart infusion (BHI) agar plates (Himedia, Mumbai, India) supplemented with $6.5 \% \mathrm{NaCl}$, incubated for $48 \mathrm{~h}$ at $37^{\circ} \mathrm{C}$.

Fifteen colonies were randomly selected from each fecal sample. Phenotypic criteria (size/volume, shape, color, gram staining, catalase production and bile aesculin reaction) were used to separate the enterococci group and the non-enterococcal strains. Selected pure colonies were stored at $-20{ }^{\circ} \mathrm{C}$ in a $10 \%(\mathrm{w} / \mathrm{v})$ solution of skim milk (Difco, Sparks, MD, USA) and $10 \%$ (v/v) glycerol (Neon Comercial Ltda, São Paulo, SP, BR).

Genomic DNA was extracted by physicochemical method as previously described by Depardieu, Perichon \& Courvalin (2004). Polymerase chain reaction (PCR) assay was carried out using genus-specific primers targeting the tuf gene, which encodes elongation factor EF-Tu (Ke et al., 1999) (Table 1). Amplifications were performed in a total volume of $25 \mu \mathrm{L}$ containing: $100 \mathrm{ng}$ of template DNA, $1 \mathrm{X}$ reaction buffer (Ludwig Biotechnology), $0.4 \mu \mathrm{M}$ of each primer (Ludwig Biotechnology), $1.5 \mathrm{mM} \mathrm{MgCl}_{2}, 200 \mu \mathrm{M}$ of dNTP (Ludwig Biotechnology), 1 U Taq DNA polymerase (Ludwig Biotechnology), and MilliQ water. Amplification was carried out in a conventional thermocycler (Applied Biosystems 2720 Thermal Cycler) according to the following program: initial denaturation at $95{ }^{\circ} \mathrm{C}$ for $3 \mathrm{~min}$, followed by 35 cycles of $95{ }^{\circ} \mathrm{C}$ for $30 \mathrm{sec}, 54{ }^{\circ} \mathrm{C}$ for $30 \mathrm{sec}$ and $72{ }^{\circ} \mathrm{C}$ for $1 \mathrm{~min}$, and a final extension at $72{ }^{\circ} \mathrm{C}$ for $7 \mathrm{~min}$. The PCR products were visualized using electrophoresis on $1.5 \%$ $(w / v)$ agarose gel, stained with SYBR® Safe DNA Gel, and visualized on a photocumenter. $E$. faecalis ATCC 29212 was used as positive control.

\section{Characterization of enterococci species}

Isolates were screened with the species-specific PCR assay for Enterococcus faecalis, Enterococcus faecium, Enterococcus casseliflavus and Enterococcus mundtii (Cheng et al., 1997; Jackson, Fedorka-Cray \& Barrett, 2004; Sedgley et al., 2005). The primers and annealing temperature used are listed in Table 1. Amplifications were prepared as described to tuf gene. PCR amplification was performed in the conventional thermocycler (Applied Biosystems 2720 Thermal Cycler) according to the following program: $94{ }^{\circ} \mathrm{C}$ for $5 \mathrm{~min}$ followed by 35 cycles of $94{ }^{\circ} \mathrm{C}$ for $1 \mathrm{~min}$, appropriate annealing temperature for each species for $1 \mathrm{~min}$, extension at $72{ }^{\circ} \mathrm{C}$ for $1 \mathrm{~min}$, and a final extension at $72{ }^{\circ} \mathrm{C}$ for $5 \mathrm{~min}$. The DNA fragment amplified by PCR was analyzed in $1.5 \%(\mathrm{w} / \mathrm{v})$ agarose gels stained with SYBR ${ }^{\circledR}$ Safe DNA Gel, and visualized on a photocumenter. 
197

198

199

200

201

202

203

204

205

206

207

208

209

210

211

212

213

214

215

216

217

218

219

220

221

222

223

224

225

226

227

228

229

230

231

232

233

234

235

Strains that were not identified by PCR reactions were submitted to matrix-assisted laser desorption and ionization time-of-flight technique (MALDI-TOF) applied to Enterococcus sp., according to Sauget et al. (2017).

Isolates classified as Enterococcus sp. were identified by Sanger sequence analysis. The PCR product of $16 S$ rRNA gene, using the 8F and R1522 primers (Coenye et al., 1999) (Table 1), was purified with Illustra ${ }^{\mathrm{TM}}$ GFX ${ }^{\mathrm{TM}}$ PCR DNA and gel band purification kit (GE Healthcare, Buckinghamshire, UK). To perform Sanger sequencing two additional primers, 519F and 926R, were used (Coenye et al., 1999) (Table 1). Sequencing was performed with the ABI PRISM® BigDye ${ }^{\circledR}$ Primer Cycle Sequencing Ready Reaction Kit in an ABI PRISM ${ }^{\circledR} 3100$ Genetic Analyzer (Applied Biosystems ${ }^{\circledR}$ ), according to the manufacturer's protocol.. The sequence obtained was compared to nucleotide sequences of reference enterococci strains deposited in GenBank.

\section{Antimicrobial susceptibility testing}

Antimicrobial susceptibilities were determined by Kirby-Bauer disk diffusion method recommended by the Clinical and Laboratory Standards Institute (CLSI, 2016). Eleven antibiotics used in clinical and veterinary medicine were tested: ampicillin $10 \mu \mathrm{g}$ (AMP), vancomycin $30 \mu \mathrm{g}(\mathrm{VAN})$, erythromycin $15 \mu \mathrm{g}$ (ERY), tetracycline $30 \mu \mathrm{g}$ (TET), ciprofloxacin 5 $\mu \mathrm{g}$ (CIP), norfloxacin $10 \mu \mathrm{g}$ (NOR), nitrofurantoin $300 \mu \mathrm{g}$ (NIT), rifampicin $5 \mu \mathrm{g}$ (RIF), chloramphenicol $30 \mu \mathrm{g}(\mathrm{CHL})$, gentamicin $120 \mu \mathrm{g}(\mathrm{GEN})$ and streptomycin $300 \mu \mathrm{g}$ (STR).

Intermediate and resistant strains were considered in a single category and classified as resistant. Strains showing resistance to three or more unrelated antibiotics were considered as multidrug-resistant (MDR) (Schwarz et al., 2010).

\section{Detection of resistance and virulence genes}

Erythromycin-resistant strains were tested by PCR for the presence of resistance encoding genes more commonly associated to clinical and environmental enterococci: $\operatorname{erm}(\mathrm{B})$, which encodes a ribosomal methylase that mediates MLSB resistance; and msrC, which encodes for a macrolide and streptogtamin B efflux pump. The presence of virulence associated genes gelE (gelatinase enzyme), cylA (activator of cytolysin), ace (accessory colonization factor), esp (associated to biofilm formation) and agg (aggregation substance) was determined by PCR in all enterococcal isolates. The amplifications were performed as described in Prichula et al. (2016). Amplifications were prepared as described to tuf gene. PCR amplification was performed in the conventional thermocycler (Applied Biosystems 2720 Thermal Cycler) according to the following program: $94{ }^{\circ} \mathrm{C}$ for $3 \mathrm{~min}$ followed by 35 cycles of $94{ }^{\circ} \mathrm{C}$ for $1 \mathrm{~min}$, appropriate annealing temperature for each resistance or virulence gene for $1 \mathrm{~min}$, extension at $72{ }^{\circ} \mathrm{C}$ for 1 min, followed by final extension at $72{ }^{\circ} \mathrm{C}$ for $5 \mathrm{~min}$. The DNA fragment amplified by PCR was analyzed in $1.5 \%(\mathrm{w} / \mathrm{v})$ agarose gels stained with SYBR® Safe DNA Gel, and visualized on a photocumenter. The sequences of the primers and annealing temperature are described in Table 1.

\section{Molecular typing of Enterococci by Pulsed-field gel electrophoresis (PFGE)}


236

237

238

239

240

241

242

243

244

245

246

247

248

249

250

251

252

253

254

255

256

257

258

259

260

261

262

263

264

265

266

267

268

269

270

271

272

273

274

Eight six enterococci strains isolated from siblings and non-sibling caterpillars were selected for PFGE analysis according to the following criteria: maternal origin (females HEAB2, HEV2 or HES2), hatched larvae, enterococcal species and antimicrobial profile. Chromosomal DNA extraction and electrophoresis conditions were prepared according to Murray et al. (1990) and Saeedi et al. (2002). The restriction enzyme used was SmaI (Invitrogen®). The electrophoresis was carried out using a clamped homogeneous electric field (CHEF-DRII device; Bio-Rad Laboratories, Richmond, Calif.), with ramped pulse times recommended by Saeedi et al. (2002) at $11^{\circ} \mathrm{C}$. Lambda Ladder PFG Marker (New England Biolabs) was used. The gels were stained with ethidium bromide $(0.5 \mu \mathrm{g} / \mathrm{mL}$ for $20 \mathrm{~min})$. The PFGE patterns were interpreted using the program GelCompar II v. 116.6 , with 1.0\% of tolerance, and the percentage of similarity was estimated using the Dice coefficient. The pulsotypes were clustered using the unweighted pair group whit arithmetic averages (UPGMA). A dendrogram was generated to examine the relatedness of PFGE patterns for selected isolates, and cutoff level of $80 \%$ applied to this dendrogram (Tenover et al., 1995).

\section{Statistical Analysis}

Simpson's index of diversity (D) was calculated to assess the differentiation of enterococci species among the caterpillars from different maternal origins (Hunter \& Gaston, $1988)$.

\section{Results}

\section{Enterococci species present in fecal samples of Heliconius erato phyllis caterpillars}

A total of 178 strains of Enterococcus were isolated from fecal samples from fifth-instar caterpillars (Table 2). Enterococcus casseliflavus was the most common species identified $(74.15 \% ; \mathrm{n}=132)$, followed by E. mundtii $(21.34 \% ; \mathrm{n}=38)$ and E. faecalis $(1.12 \% ; \mathrm{n}=2)$. Six strains $(3.37 \%)$ could not be identified to species level.

Differences in the composition of enterococci were detected between the three groups of caterpillars, as shown in Table 2. The Simpson's diversity index was different between the three populations, with higher diversity of enterococci species from fecal samples of caterpillars from HES2 $(1-\mathrm{D}=0.68)$, followed by HEV2 $(1-\mathrm{D}=0.49)$ and HEAB2 $(1-\mathrm{D}=0.27)$.

\section{Antimicrobial susceptibility}

One hundred and twenty $(67.41 \%)$ enterococci were resistant to at least one evaluated antimicrobial agent. The frequency of antibiotic-susceptible strains is shown in Table 3 . The rifampicin-resistance phenotype was the most commonly observed $(56 \% ; n=100)$, followed by erythromycin $(31 \% ; n=55)$. Eight strains $(4 \%)$ were resistant to norfloxacin and five $(3 \%)$ to ciprofloxacin. All investigated strains were susceptible to ampicillin, vancomycin, tetracycline, nitrofurantoin, chloramphenicol, gentamicin, and streptomycin.

Single- (SR), double- (DR), and multiple-drug resistance (MDR) were observed in 67\% $(\mathrm{n}=80), 28 \%(\mathrm{n}=34)$, and $5 \%(\mathrm{n}=6)$ of strains, respectively, of the 120 resistant strains.

\section{Determinates of resistance and virulence}


275

276

277

278

279

280

281

282

283

284

285

286

287

288

289

290

291

292

293

294

295

296

297

298

299

300

301

302

303

304

305

306

307

308

309

310

311

312

313

314

None of the 55 erythromycin-resistant strains was positive for $\operatorname{erm}(\mathrm{B})$ and $m s r \mathrm{C}$ genes. The presence of virulence genes was evaluated in all strains, and the esp gene was detected in $35.39 \%(\mathrm{n}=63)$, ace in $6.74 \%(\mathrm{n}=12)$ and gelE in $1.12 \%(\mathrm{n}=2)$. No strain was positive for the clyA and agg genes.

\section{Genetic relationships between enterococci isolated from sibling and non-sibling caterpillars in} the fifth-instar

Of the 178 strains isolated, 86 (E. casseliflavus, $\mathrm{n}=58 ;$ E. mundtii, $\mathrm{n}=23 ;$ E. faecalis, $\mathrm{n}$ $=2$; and Enterococcus sp., $\mathrm{n}=3$ ) were chosen for PFGE (Table S1). From the sibling caterpillars, numbered 6,7,10,11 and 14, of the HEAB2 female were picked E. casseliflavus (n =32), E. mundtii $(\mathrm{n}=8)$ and E. faecalis $(\mathrm{n}=2)$. All strains were isolated from caterpillars hatched closely in time and fed the same batch of $P$. suberosa leaves. From the offspring of the HEV2 female (sibling caterpillars 9, 18, 26, 27, and 29) E. casseliflavus $(\mathrm{n}=19)$, E. mundtii $(\mathrm{n}=$ 9) and Enterococcus sp. $(\mathrm{n}=3)$ were selected. These isolates were recovered from siblings that hatched at different times and were fed different batches of leaves. From the offspring of the HES2 female (sibling caterpillars 3 and 17) E. casseliflavus $(\mathrm{n}=7)$ and E. mundtii $(\mathrm{n}=6)$ were selected.

The hierarchical relationship between enterococci selected from sibling and non-sibling caterpillars showed 22 patterns (15 patterns and 7 single strain-[singleton]; Fig. 2). Four patterns generated by PFGE indicated a genetic relationship between strains isolated from sibling caterpillars (P7, P8, P9, and P13); 11 were composed of strains isolated from the same caterpillars (P1, P2, P3, P4, P5, P6, P10, P11, P12, P14, and P15). No genetic relationships were observed for strains isolated from non-siblings.

The band patterns for E. casseliflavus $(\mathrm{n}=32)$ isolates from sibling caterpillars $(6,7,10$ 11 and 14) of the HEAB2 female showed six PFGE patterns (P5, P7, P8, P9, P11 and P12) and three singletons. Three PFGE patterns (P7, P8, and P9) included 18 of the 32 strains that were isolated from sibling caterpillars 6, 7, 10, and/or 11, with low levels of genetic variability. P5 and P11 each contained two isolates, and P12 with eight isolates showed genetic variation; the remaining three E. casseliflavus isolates were singletons and represented unique PFGE patterns. All E. mundtii isolates from caterpillar 14 were genetically closely related and were clustered into one pattern (P10), as were the two E. faecalis $(\mathrm{P} 3)$ isolates from caterpillar 6. These results demonstrate that strains may originate from a single lineage.

Seven different PFGE patterns (P4, P6, P13, P15, and three singletons) were obtained from sibling caterpillars 9, 18, 26, 27, and 29 of the HEV2 female. The analysis of the fragment profiles of the E. mundtii $(\mathrm{n}=9)$ and Enterococcus $\mathrm{sp} .(\mathrm{n}=1)$ strains isolated from caterpillars 18, 26, 27, and 29 demonstrated a genetic relationship between them (P13). The $19 E$. casseliflavus strains showed four PFGE patterns: P4, P6, and P15, each containing six, three, and nine isolates, respectively, and one singleton. These distinct patterns are suggestive of genetic events in these strains.

The seven E. casseliflavus strains from caterpillars 3 and 17 (offspring of the HES2 female) showed two distinct patterns (P1 and P2) with 100\% of genetic similarity between them. 
$315 \mathrm{P} 1$ contained four isolates and $\mathrm{P} 2$ had three isolates. Of the six E. mundtii isolates from 316 caterpillar 3, five showed 100\% similarity and were clustered in the P14 pattern, suggesting that 317 these strains may be progeny from a single lineage. One strain had distinct and unrelated PFGE 318 by the criteria of Tenover et al. (1999). In addition, most of the patterns were shared by isolates 319 with the same antimicrobial profile.

320

321

322

323

324

325

326

327

328

329

330

331

332

333

334

335

336

337

338

339

340

341

342

343

344

345

346

347

348

349

350

351

352

353

354

\section{Discussion}

An increasing number of studies have aimed to investigate the microbial communities in the GI tract of insects. In the Lepidoptera, a high abundance of Enterococcus has been found, both in immatures and adults, raising questions about the role of these bacteria in invertebrates and their importance in maintaining the health of individuals (Hammer, McMillan \& Fierer, 2014; Holt et al., 2015; Chen et al., 2016; Snyman et al., 2016; Shao et al., 2017; van Schooten et al., 2018; Allonsius et al., 2019). To our knowledge, only Hammer, McMillan \& Fierer (2014) and, more recently, van Schooten et al. (2018) have addressed the microbial communities in the Heliconius GI tract, and have reported that the genus Enterococcus is dominant in microbial samples from different Heliconius species.

Enterococcus is associated with the environment and a wide range of organisms, including plants (Müller et al., 2001; Byappanahalli et al., 2012; Sánchez Valenzuela et al., 2012). In the present study, the most abundant Enterococcus species in the feces of $H$. erato phyllis caterpillars was E. casseliflavus. The diet of insects constitutes an additional source of microorganisms in the GI tract. Enterococci in the GI tract of caterpillars can play an important role in the protection against other pathogens, since these bacteria are able to produce lactic acid (causing a decrease in $\mathrm{pH}$ ) and enterocins (peptides with antimicrobial activity). Since $E$. casseliflavus is frequently a part of microbial communities on plants (Byappanahalli et al., 2012; Micallef et al., 2013; Ong et al., 2014), the predominance of this species in fecal samples of $H$. erato phyllis caterpillars could be explained by the plant diet of juveniles, resulting in the dominance of this species. As noted by Chen et al. (2016), enterococci stably colonize the larval gut of Spodoptera littoralis (Lepidoptera: Noctuidae), and may act beneficially in caterpillars by promoting nutrient supplementation (metabolism of terpenoids and polyketides) and host defense (production of antimicrobials by E. mundtii). However, further studies are needed to understand the role of these bacteria as members of the GI tract in H. erato phyllis caterpillars.

Resistant enterococcal strains isolated from fecal samples of caterpillars are a matter of concern, since these larvae had not been exposed to antibiotics. Studies that highlight the resistance profile of enterococci isolated from insects in natural environments are scarce. Channaiah et al. (2010) described enterococci isolated from insect pests of stored products; they were resistant to tetracycline, streptomycin, erythromycin, kanamycin, ciprofloxacin, ampicillin, and chloramphenicol; this suggests that these animals can be potential vectors in disseminating antibiotic-resistant strains. Ahmad et al. (2011) reported MDR enterococci isolated from house flies and cockroaches in a confined swine production environment, and have suggested that these insects may be potential vectors and/or reservoirs of resistant enterococci. Despite the occurrence

Peer) reviewing PDF | (2019:09:41227:1:1:NEW 18 Dec 2019) 
355

356

357

358

359

360

361

362

363

364

365

366

367

368

369

370

371

372

373

374

375

376

377

378

379

380

381

382

383

384

385

386

387

388

389

390

391

392

393

394

and spread of resistant strains intensifying due to the use of antimicrobials, the isolation of resistant enterococci in the present study could be related to the resistance that occurs naturally in the environment (environmental resistome) and/or to anthropogenic activities (contamination of the environment) (Martinez, 2008; Allen et al., 2010).

The most widespread mechanism of resistance to macrolides in enterococci is mediated by the erm and $m s r C$ genes (Aarestrup et al., 2000; Santestevan et al., 2015; Prichula et al., 2016). Nevertheless, none of these genes was detected in the present study. It is possible that these strains harbored other erythromycin-resistance genes, such as ermD, E, and F, and other efflux pump genes such as $m s r A$. A low percentage of virulence genes was detected in enterococci of $H$. erato phyllis caterpillars. Although these genes are related to pathogenicity of clinical enterococcal strains, their presence in strains in fecal samples from caterpillars may be associated with the maintenance of cells of the GI tract, and consequently with microorganism and host interactions.

From the analysis of the PFGE fingerprint, E. casseliflavus, E. faecalis, E. mundtii, and Enterococcus sp. isolated from fecal samples of sibling and non-sibling caterpillars demonstrated unrelated or related patterns based on maternal origin. The unrelated patterns found in P1, P2, P3, P4, P5, P6, P10, P11, P12, P14, and P15 demonstrated genetic diversity among these strains. The genetic variation in these strains may be associated with genetic events, such as mobile elements or mutation, a common characteristic of enterococci (Lebreton et al., 2014). The related patterns observed among strains isolated from sibling caterpillars (P7, P8, P9, and P13) may be associated with a common source, e.g., diet (herbivory) and/or vertical transmission (through the egg surface). Since the fecal samples used in the present study were collected from fifth-instar caterpillars, the last stage before the pupa, the results present here may be suggest vertical transmission of enterococci that are being replaced from the diet. Plants are a food source for bacteria present in the GI tract of insects; these bacteria improve the quality of diets poor in nutrients and take part in development and maturation of the immune system to protect the host against pathogenic microorganisms (Dillon \& Dillon, 2004; Engel \& Moran, 2013). Therefore, it is likely that herbivory provides an abundant supply of enterococci throughout the larval stage of H. erato phyllis. Considering that Passiflora leaves are the only food of the caterpillars, those leaves could be the source of Enterococcus sp. in their GI tracts.

Besides the diet, vertical transmission from the female to her offspring can also be a source of bacteria. Some studies have described the mechanism for vertical transmission of bacteria in different species of Lepidoptera (Brinkmann, Martens \& Tebbe, 2008; Chen et al., 2016; Teh et al., 2016; Shao et al., 2017). The caterpillar hatches by chewing a hole in the chorion and emerging through it from the egg. Brinkmann, Martens \& Tebbe (2008) reported that the Enterococcus spp. present in the gut of the larvae of Manduca sexta (Lepidoptera: Sphingidae) were acquired via ingestion of their eggshell, demonstrating maternal transmission of microorganisms. Chen et al. (2016) analyzed the composition and activity of microbiota in the moth Spodoptera littoralis, which is an agricultural pest; they found that enterococci associated with adult females were also in the egg mass, and further colonized the larval gut of individuals, 
395

396

397

398

399

400

401

402

403

404

405

406

407

408

409

410

411

412

413

414

415

416

417

418

419

420

421

422

423

424

425

426

427

428

429

430

431

432

suggesting vertical transmission of these bacteria. Teh et al. (2016) showed the route of transmission of E. mundtii in S. littoralis when administered in vivo; the authors reported the presence of $E$. mundtii at all life stages of this insect. In addition, they established the presence of these bacteria in oocytes and the muscle tissue in the first-instar larvae of the second-generation offspring, highlighting again the vertical transmission of enterococci in this lepidopteran. The enterococci isolated in the present study may be linked to herbivory; however, although our analysis does not include adult females and the bacterial communities of Passiflora leaves, we do not rule out the possibility that enterococci could also be transmitted from the female to the offspring through the surface of the egg, as previously demonstrated for other species of Lepidoptera.

\section{Conclusions}

Enterococcus casseliflavus was the dominant enterococcal species isolated in fecal samples of the fifth-instar caterpillars of $H$. erato phyllis. Resistant strains present in the caterpillars studied may be related to the environmental resistome and/or anthropogenic activity. In addition, the presence of MDR enterococci may be an indication of contamination of the environmental by antibiotics. The results obtained by PFGE analysis suggest that the enterococci isolated from fecal samples of sibling caterpillars might have come from common sources, e.g., the diet (herbivory) and/or vertical transmission (through the egg surface). Further studies will be conducted to better understand the role of Enterococcus in the GI tract microbial community of H. erato phyllis butterflies, and the mechanisms involved in acquisition and maintenance of these bacteria. In addition, the data obtained can be used in future comparative analyses of the microbiota present in adult $H$. erato phyllis females and their offspring, to confirm the occurrence of vertical transmission of Enterococcus sp. in this model organism.

\section{Acknowledgements}

We thank to Lucas de Oliveira Einsfeld and Gabriella Oliveira de Araújo for the drawing, we thank also Conselho Nacional de Desenvolvimento Científico e Tecnológico do Brasil and Coordenação de Aperfeiçoamento de Pessoal de Nível Superior (CAPES).

\section{References}

Aarestrup, F.M., Agerso, Y., Gerner-Smidt, P., Madsen, M., Jensen, L.B. (2000) Comparison of antimicrobial resistance phenotypes and resistance genes in Enterococcus faecalis and Enterococcus faecium from humans in the community, broilers, and pigs in Denmark. Diagn. Microbiol Infect Dis 37(2): 127-137.

Ahmad, A., Ghosh, A., Schal, C., Zurek, L. (2011) Insects in confined swine operations carry a large antibiotic resistant and potentially virulent enterococcal community. BMC Microbiol 11(1): 23. 
433 Allen, H.K., Cloud-Hansen, K.A., Wolinski, J.M., Guan, C., Greene, S., Lu, S., Boeyink, M., 434 Broderick, N.A., Raffa, K.F., Handelsman, J. (2009) Resident microbiota of the gypsy moth 435 midgut harbors antibiotic resistance determinants. DNA Cell Biol 28(3): 109-117.

436 Allen, H.K., Donato, J., Wang, H.H., Cloud-Hansen, K.A., Davies, J., Handelsman, J. (2010) 437 Call of the wild: antibiotic resistance genes in natural environments. Nat Rev Microbiol 8(4): 438 251-259.

439 Allonsius, C.N., Van Beeck, W., De Boeck, I., Wittouck, S., Lebeer, S. (2019) The microbiome 440 of the invertebrate model host Galleria mellonella is dominated by Enterococcus. BMC Animal 441 Microbiome 1:7.

442 Aslam, B., Wang, W., Arshad, M.I., Khurshid, M., Muzammil, S., Rasool M.H., Nisar, N.A., 443 Alvi, R.F., Aslam, M.A., Qamar, M.U., Salamat M.K.F., Baloch, Z. (2018) Antibiotic resistance: 444 a rundown of a global crisis. Infect Drug Resist 11: 1645-1658.

445 Audisio, M.C., Torres, M.J., Sabaté, D.C., Ibarguren, C., Apella, M.C. (2011) Properties of 446 different lactic acid bacteria isolated from Apis mellifera L. bee-gut. Microbiol Res 166(1): 1-13. 447 Brinkmann, N., Martens, R., Tebbe, C.C. (2008) Origin and diversity of metabolically active gut 448 bacteria from laboratory-bred larvae of Manduca sexta (Sphingidae, Lepidoptera, Insecta). Appl 449 Environ Microbiol 74(23): 7189-7196.

450 Brown, K.S. (1981) The biology of Heliconius and related genera. Annu Rev Entomol 26: 427451456.

452 Byappanahalli, M.N., Nevers, M.B., Korajkic, A., Staley, Z.R., Harwood, V.J. (2012) 453 Enterococci in the environment. Microbiol Mol Biol Rev 76(4): 685-706.

454 Channaiah, L.H., Subramanyam, B., McKinney, L.J., Zurek, L. (2010) Stored-product insects 455 carry antibiotic-resistant and potentially virulent enterococci. FEMS Microbiol Ecol 74(2): 464456471.

457 Chen, B., Teh, B., Sun, C., Hu, S., Lu, X., Boland, W., Shao, Y. (2016) Biodiversity and activity 458 of the gut microbiota across the life history of the insect herbivore Spodoptera littoralis. Sci Rep 459 6: 29505.

460 Cheng, S., McCleskey, F.K., Gress, M.J., Petroziello, J.M., Liu, R., Namdari, H., Beninga, K., 461 Salmen, A., Delvecchio, V.G. (1997) A PCR assay for identification of Enterococcus faecium. J 462 Clin Microbiol 35(5): 1248-1250.

463 Clinical and Laboratory Standards Institute (CLSI). (2016) Performance Standards for 464 Antimicrobial Susceptibility Testing - Twelve-Six Edition 100S. Wayne, PA: CLSI.

465 Coenye, T., Falsen, E., Vancanneyt, M., Hoste, B., Govan, J.R.W., Kersters, K., Vandamme, P. 466 (1999) Classification of Alcaligenes faecalis-like isolates from the environment and human 467 clinical samples as Ralstonia gilardii sp. nov. Int J Syst Bacteriol 49(2): 405-413.

468 De Nardin, J., Da Silva, L., Araújo, A.M. (2016) Kin recognition in a butterfly: inferences about 469 its heritability. Ethol Ecol Evol 29(3): 1-11.

470 Depardieu, F., Perichon, B., Courvalin, P. (2004) Detection of the van Alphabet and 471 identification of enterococci and staphylococci at the species level by multiplex PCR. J Clin 472 Microbiol 42(12): 5857-5860. 
473 Dillon, R.J., Dillon, V.M. (2004) The gut bacteria of insects: nonpathogenic interactions. Annu 474 Rev Entomol 49: 71-92.

475 Douglas, A.E. (2015) Multiorganismal insects: diversity and function of resident 476 microorganisms. Annu Rev Entomol 60: 17-34.

477 Douglas, A.E. (2018) Gut microbes alter fly walking activity. Nature 563: 331-333.

478 Eaton, T.J., Gasson, M.J. (2001) Molecular screening of Enterococcus virulence determinants 479 and potential for genetic exchange between food and medical isolates. Appl Environ 480 Microbiol 67(4): 1628-1635.

481 Engel, P., Moran, N.A. (2013) The gut microbiota of insects - diversity in structure and function. 482 FEMS Microbiol Rev 37(5): 699-735.

483 Ferri, M., Ranucci, E., Romagnoli, P., Giaccone, V. (2017) Antimicrobial resistance: A global 484 emerging threat to public health systems. Crit Rev Food Sci Nutr 57(13): 2857-2876.

485 Gilbert, L.E. (1972) Pollen Feeding and Reproductive Biology of Heliconius Butterflies. Proc 486 Nat Acad Sci 69(6): 1403-1407.

487 Ghosh, A., Akhtar, M., Holderman, C., Zurek, L. (2014) Significance and survival of enterococci 488 during the house fly development. J Med Entomol 51(1): 63-67.

489 Gothwal, R., Shashidhar, T. (2014) Antibiotic pollution in the environment: a review. Clean 43: 490 479-489.

491 Hammer, T.J., McMillan, W.O., Fierer, N. (2014) Metamorphosis of a butterfly-associated 492 bacterial community. PLoS One 9: e86995.

493 Hay-Roe, M.M., Nation, J. (2007) Spectrum of cyanide toxicity and allocation in Heliconius 494 erato and Passiflora host plants. J Chem Ecol 33(2): 319-329.

495 Hollenbeck, B.L., Rice, L.B. (2012) Intrinsic and acquired resistance mechanisms in 496 enterococcus. Virulence 3(5): 421-433.

497 Holt, J.F., Kiedrowski, M.R., Frank, K.L., Du, J., Guan, C., Broderick, N.A., Dunny, G.M., 498 Handelsman, J. (2015) Enterococcus faecalis 6-Phosphogluconolactonase is required for both 499 commensal and pathogenic interactions with Manduca sexta. Infect Immun 83(1): 396-404.

500 Hunter, P.R., Gaston, M.A. (1988) Numerical index of the discriminatory ability of typing 501 systems: an application of Simpson's index of diversity. J Clin Microb 26(11): 2465-2466.

502 Jackson, C.R., Fedorka-Cray, P.J., Barrett, J.B. (2004) Use of a genus- and species-specific 503 multiplex PCR for identification of Enterococci. J Clin Microbiol 42: 3558-3565.

504 Ke, D., Picard, F.J., Martineau, F., Menard, C., Roy, P.H., Ouellette, M., Bergeron, M.G. (1999) 505 Development of a PCR assay for rapid detection of enterococci. J Clin Microbiol 37(11): 34975063503.

507 Kim, J.M., Choi, M.Y., Kim, J.W., Lee, S.A., Ahn, J.H., Song, J., Kim, S.H., Weon, H.Y. (2017) 508 Effects of diet type, developmental stage, and gut compartment in the gut bacterial communities 509 of two Cerambycidae species (Coleoptera). J Microbiol 55(1): 21-30.

510 Lebreton, F., Willems, R.J.L., Gilmore, M.S. (2014) "Enterococcus Diversity, Origins in Nature, 511 and Gut Colonization”. In Gilmore, M.S., Clewell, D.B., Ike, Y., Shankar, N., editors. 
512 Enterococci: From Commensals to Leading Causes of Drug Resistant Infection, Massachusetts, 513 USA: Eye and Ear Infirmary. P. 1-82.

514 Lowe, C.F., Romney, M.G. (2011) Bedbugs as Vectors for Drug-Resistant Bacteria. Emerg 515 Infect Dis 17(6): 1132-1134.

516 Macovei, L, Zurek, L. (2006) Ecology of antibiotic resistance genes: characterization of 517 enterococci from houseflies collected in food settings. Appl Environ Microbiol 72(6): 40285184035.

519 Mannu, L., Paba, A., Daga, E., Comunian, R., Zanetti, S., Duprè, I., Sechi, L.A. 520 (2003) Comparison of the incidence of virulence determinants and antibiotic resistance 521 between Enterococcus faecium strains of dairy, animal and clinical origin. Int J Food Microbiol 522 88: 291-304.

523 Martínez, J.L. (2008) Antibiotics and antibiotic resistance genes in natural environments. 524 Science 321(5887): 365-367.

525 Merril, R.M., Dasmahapatra, K.K., Davey, J.W., Dell'Aglio, D.D., Hanly, J.J., Huber, B., 526 Jiggins, C.D., Joron, M., Kozak, K.M., Llauren, V., Martin, S.H., Montgomery, S.H., Morris, J., 527 Nadeau, N.J., Pinharanda, A.L., Rosser, N., Thompson, M.J, Vanjari, S., Wallbank, R.W.R., Yu, 528 Q. (2015) The diversification of Heliconius butterflies: what have we learned in 150 years? J 529 Evol Biol 28(8): 1417-1438.

530 Micallef, S.A., Goldstein, R.E.R., George, A., Ewing, L., Tall, B.D., Boyer, M.S., Joseph, S.W., 531 Sapkota, A.R. (2013) Diversity, distribution and antibiotic resistance of Enterococcus spp. 532 recovered from tomatoes, leaves, water and soil on U.S. Mid-Atlantic farms. Food Microbiol 533 36(2): 465-474.

534 Moges, F., Eshetie, S., Endris, M., Huruy, K., Muluye, D., Feleke, T., G/Silassie, F., Ayalew, G., 535 Nagappan, R. (2016) Cockroaches as a source of high bacterial pathogens with multidrug 536 resistant strains in Gondar town, Ethiopia. Biomed Res Int 2825056.

537 Mohammed, A.N., Abdel-Latef, G.K., Abdel-Azeem, N.M., El-Dakhly, K.M. (2016) Ecological 538 study on antimicrobial-resistant zoonotic bacteria transmitted by flies in cattle farms. Parasitol 539 Res 115(10): 3889-3896.

540 Müller, T., Ulrich, A., Ott, E.M., Müller, M. (2001) Identification of plant-associated 541 enterococci. J Appl Microbiol 91(2): 268-278.

542 Murray, B.E., Singh, K.V., Heath, J.D., Sharma, B.R., Weinstock, G.M. (1990) Comparison of 543 genomic DNAs of different enterococcal isolates using restriction endonucleases with infrequent 544 recognition sites. J Clin Microbiol 28(9): 2059-2063.

545 Ong, Y.Y., Tan, W.S., Mohamad, R., Sieo, C.C., Tey, B.T. (2014) Biochemical and molecular 546 identification of Enterococcus spp. from red pitaya. Process Biochemistry 49(4): 563-568.

547 Onwugamba, F.C., Fitzgerald, J.R., Rochon, K., Guardabassi, L., Alabi, A., Kühne, S., 548 Grobusche, M.P., Schaumburg, F. (2018) The role of 'Filth Flies' in the spread of antimicrobial 549 resistance. Travel Med Infect Dis 22: 8-17.

550 Pai H. (2013) Multidrug resistant bacteria isolated from cockroaches in long-term care facilities 551 and nursing homes. Acta Trop 125(1): 18-22. 
552 Prichula, J., Pereira, R.I., Wachholz, G.R., Cardoso, L.A., Tolfo, N.C., Santestevan, N.A., 553 Medeiros, A.W., Tavares, M., Frazzon, J., d'Azevedo, P.A., Frazzon, A.P.G. (2016) Resistance 554 to antimicrobial agents among enterococci isolated from fecal samples of wild marine species in 555 the southern coast of Brazil. Mar Pollut Bull 105(1): 51-57.

556 Saeedi, B., Hällgren, A., Jonasson, J., Nilsson, L.E., Hanberger, H., Isaksson, B. (2002) 557 Modified pulsed-field gel electrophoresis protocol for typing of enterococci. APMIS 110(12): 558 869-874.

559 Sánchez Valenzuela, A., Benomar, N., Abriouel, H., Pérez Pulido, R., Martínez Cañamero, M., 560 Gálvez, A. (2012) Characterization of Enterococcus faecalis and Enterococcus faecium from 561 wild flowers. Antonie Van Leeuwenhoek 101(4): 701-711.

562 Santestevan, N.A., de Angelis, D.Z., Prichula, J., Pereira, R.I., Wachholz, G.R., Cardoso, 563 L.A., de Moura, T.M., Medeiros, A.W., de Amorin, D.B., Tavares, M., d'Azevedo, P.A., Franco, 564 A.C., Frazzon, J., Frazzon, A.P.G. (2015) Antimicrobial resistance and virulence factor gene 565 profiles of Enterococcus spp. isolates from wild Arctocephalus australis (South American fur 566 seal) and Arctocephalus tropicalis (Subantarctic fur seal). World J Microbiol Biotechnol 31(12): $567 \quad 1935-1946$.

568 Sauget, M., Valot, B., Bertrand, X., Hocquet, D. (2017) Can MALDI-TOF mass spectrometry 569 reasonably type bacteria? Trends Microbiol 25(6): 447-455.

570 Schaumburg, F., Onwugamba, F.C., Akulenko, R., Peters, G., Mellmann, A., Köck, R., Becker, 571 K. (2016) A geospatial analysis of flies and the spread of antimicrobial resistant bacteria. Int J 572 Med Microbiol 306(7): 566-571.

573 Schwarz, S., Silley, P., Simjee, S., Woodford, N., van Duijkeren, E., Johnson, A.P., Gaastra, W. 574 (2010) Editorial: assessing the antimicrobial susceptibility of bacteria obtained from animals. J 575 Antimicrob Chemother 65(4): 601-604.

576 Sedgley, C., Nagel, A., Shelburne, C.E., Clewell, D.B., Appelbe, O., Molander, A. (2005) 577 Quantitative real-time PCR detection of oral Enterococcus faecalis in humans. Arch Oral 578 Biol 50(6): 575-583.

579 Shankar, V., Baghdayan, A.S., Huycke, M.M., Lindahl, G., Gilmore, M.S. (1999) Infection580 derived Enterococcus faecalis strains are enriched in esp, a gene encoding a novel surface 581 protein. Infect Immun 67(1): 193-200.

582 Shao, Y., Chen, B., Sun, C., Ishida, K., Hertweck, C., Boland, W. (2017) Symbiont-derived 583 antimicrobials contribute to the control of the Lepidopteran gut microbiota. Cell Chem Biol 584 24(1): 66-75.

585 Singer, A.C., Shaw, H., Rhodes, V., Hart, A. (2016) Review of antimicrobial resistance in the 586 environment and its relevance to environmental regulators. Front Microbiol 7: 1728.

587 Snyman, M., Gupta, A.K., Bezuidenhout, C.C., Claassens, S., van den Berg, J. (2016) Gut 588 microbiota of Busseola fusca (Lepidoptera: Noctuidae). World J Microbiol Biotechnol 32(7): 589115.

590 Sutcliffe, J., Tait-Kamradt, A., Wondrack, L. (1996) Streptococcus pneumonia and 591 Streptococcus pyogenes resistant to macrolides but sensitive to clindamycin: a common 
592 resistance pattern mediated by an efflux system. Antimicrob Agents Chemother 40(8): 18175931824.

594 Teh, B.S., Apel, J., Shao, Y., Boland, W. (2016) Colonization of the intestinal tract of the 595 polyphagous pest Spodoptera littoralis with the GFP-tagged indigenous gut bacterium 596 Enterococcus mundtii. Front Microbiol 14: 1-12.

597 Tenover, F.C., Arbeit, R.D., Goering, R.V., Mickelsen, P.A., Murray, B.E., Persing, D.H., 598 Swaminathan, B. (1995) Interpreting chromosomal DNA restriction patterns produced by pulsed599 field gel electrophoresis: criteria for bacterial strain typing. J Clin Microbiol 33(9): 2233-2239.

600 Usui, M., Shirakawa, T., Fukuda, A., Tamura, Y. (2015) The role of flies in disseminating 601 plasmids with antimicrobial-resistance genes between farms. Microb Drug Resist 21(5): 562602569.

603 van Schooten, B., Godoy-Vitorino, F., McMillan, W.O., Papa, R. (2018) Conserved microbiota 604 among young Heliconius butterfly species. PeerJ 6: e5502.

605 Watkins, R.R., Bonomo, R.A. (2016) Overview: global and local impact of antibiotic resistance. 606 Infect Dis Clin N Am 30: 313-322.

607 Werner, G., Hildebrandt, B., Witte, W. (2001) The newly described $m s r C$ gene is not equally 608 distributed among all isolates of Enterococcus faecium. Antimicrob Agents Chemother 45(12): $609 \quad 3672-3673$.

610 Zhang, J., Wang, J., Chen, L., Yassin, A.K., Kelly, P., Butaye, P., Li, J., Gong, J., Cattley, R., Qi, 611 K., Wanga, C. (2017) Housefly (Musca Domestica) and Blow Fly (Protophormia Terraenovae) 612 as vectors of bacteria carrying colistin resistance genes. Appl Environ Microbiol 84(1) e0173661317.

614 Zurek, L., Ghosh, A. (2014) Insects represent a link between food animal farms and the urban 615 environment for antibiotic resistance traits. Appl Environ Microbiol 80(12): 3562-3567. 
Figure 1

Illustration of Heliconius erato phyllis butterflies and caterpillars used in the study.

(A) Female HEAB2 and offspring $(6,7,10,11$, and 14); (B) female HEV2 and offspring $(9,18$, 26, 27, and 29); (C) female HES2 and offspring (3 and 17). Illustration credit: Lucas de Oliveira Einsfeld and Gabriella Oliveira de Araújo.

$\mathbf{A}$
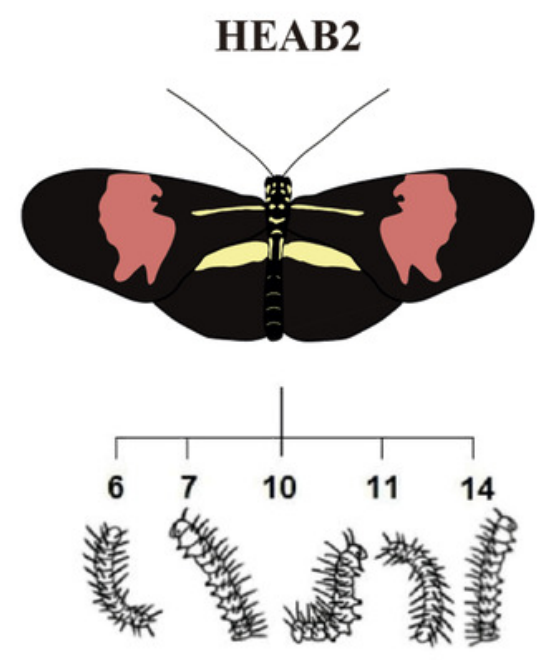

B
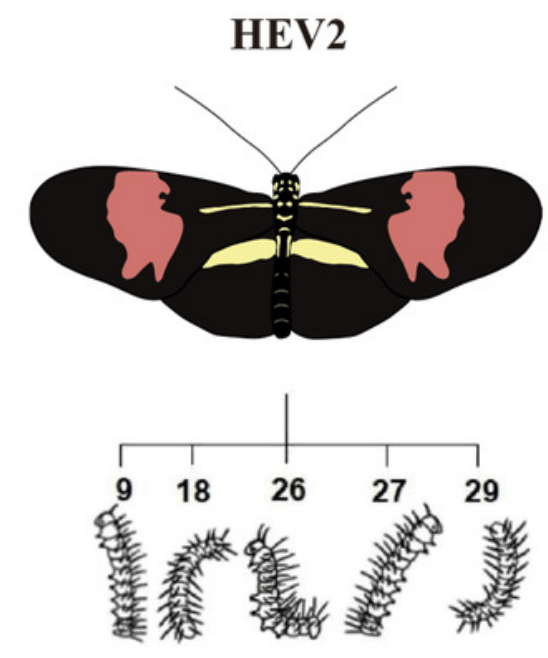

Female offspring
C

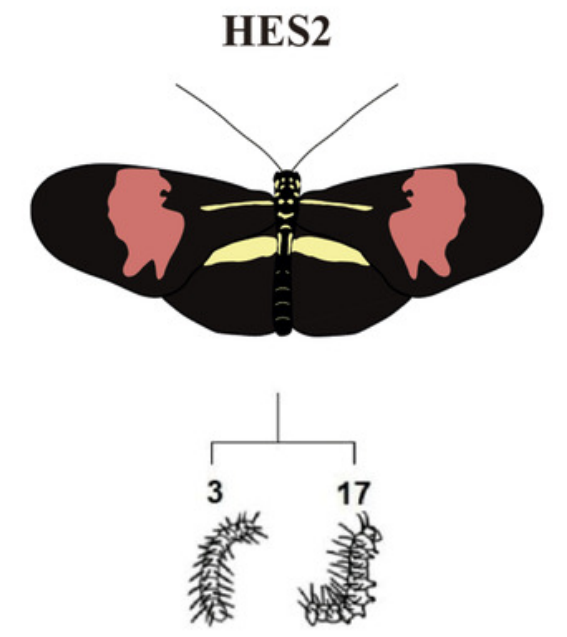


Figure 2

Dendrogram of enterococci isolated from fecal samples of Heliconius erato phyllis caterpillars.

HEAB2, H. erato phyllis from Águas Belas; HEV2, $H$ erato phyllis from Viamão; HES2, H. erato phyllis from São Francisco de Paula. Antibiotics: RIF, rifampicin; ERY, erythromycin; NOR, norfloxacin; CIP, ciprofloxacin; S, susceptible; R, resistant. 

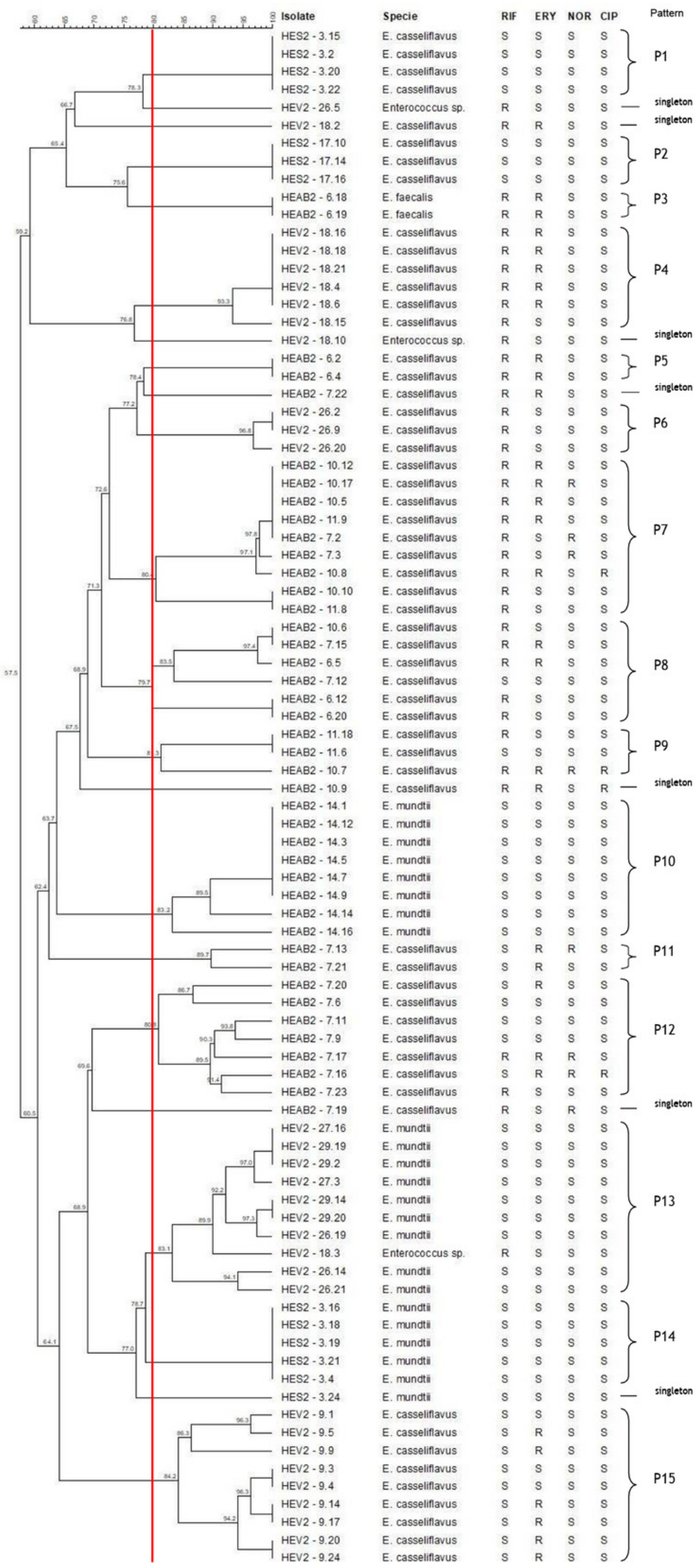
Table $\mathbf{1}$ (on next page)

Primers used in the PCRs carried out in this study 
Table 1:

Primers used in the PCRs carried out in this study.

\begin{tabular}{|c|c|c|c|c|}
\hline Primer & Nucleotide sequence (5'-3') & $\begin{array}{l}\mathrm{AT}^{1} \\
\left({ }^{\circ} \mathrm{C}\right)\end{array}$ & $\begin{array}{l}\text { Amplicon } \\
\text { (bp) }\end{array}$ & Reference \\
\hline $\begin{array}{l}\text { Genus } \\
\text { tuf-F } \\
\text { tuf-R }\end{array}$ & $\begin{array}{l}\text { TACTGACAAACCATTCATGATG } \\
\text { AACTTCGTCACCAACGCGAAC }\end{array}$ & 54 & 112 & Ke et al. (1999) \\
\hline \multicolumn{5}{|l|}{ E. faecalis } \\
\hline $\begin{array}{l}\text { E16s-F } \\
\text { E16s-R }\end{array}$ & $\begin{array}{l}\text { CCGAGTGCTTGCACTCAATTGG } \\
\text { CTCTTATGCCATGCGGCATAAAC }\end{array}$ & 66 & 138 & Sedgley et al. (2005) \\
\hline $\begin{array}{l}\text { E. faecium } \\
\text { EM1A-F } \\
\text { EM1B-R }\end{array}$ & $\begin{array}{l}\text { TTGAGGGACACCAGATTGACG } \\
\text { TATGACAGCGACTCCGATTCC }\end{array}$ & 62 & 658 & Cheng et al. (1997) \\
\hline \multicolumn{5}{|c|}{ E. casseliflavus } \\
\hline $\begin{array}{l}\text { CA1 } \\
\text { CA2 }\end{array}$ & $\begin{array}{l}\text { TCCTGAATTAGGTGAAAAAAC } \\
\text { GCTAGTTTACCGTCTTTAACG }\end{array}$ & 59 & 288 & $\begin{array}{l}\text { Jackson, Fedorka-Cray } \\
\text { \& Barrett (2004) }\end{array}$ \\
\hline \multicolumn{5}{|l|}{ E. mundtii } \\
\hline $\begin{array}{l}\text { MU1-F } \\
\text { MU2-R }\end{array}$ & $\begin{array}{l}\text { CAGACATGGATGCTATTCCATCT } \\
\text { GCCATGATTTTCCAGAAGAATG }\end{array}$ & 60 & 94 & $\begin{array}{l}\text { Jackson, Fedorka-Cray } \\
\text { \& Barrett (2004) }\end{array}$ \\
\hline \multicolumn{5}{|l|}{$16 s r R N A$} \\
\hline $8 \mathrm{~F}$ & AGAGTTTGATCCTGGCTCAG & \multirow{4}{*}{60} & \multirow{4}{*}{1514} & \multirow{4}{*}{ Coenye et al. (1999) } \\
\hline $519 \mathrm{~F}$ & CAGCAGCCGCGGTAATAC & & & \\
\hline $926 \mathrm{R}$ & CCGTCAATTCCTTTGAGTT & & & \\
\hline $1522 \mathrm{R}$ & AAGGAGGTGATCCAGCCGCA & & & \\
\hline \multicolumn{5}{|l|}{ Erythromycin } \\
\hline $\begin{array}{l}\text { erm(B)_F } \\
\text { erm(B)_R }\end{array}$ & $\begin{array}{l}\text { GAAAAGGTACTCAACCAAATA } \\
\text { AGTAACGGTACTTAAATTGTTTAC }\end{array}$ & 52 & 639 & $\begin{array}{c}\text { Sutcliffe, Tait-Kamradt \& } \\
\text { Wondrack (1996) }\end{array}$ \\
\hline $\begin{array}{l}\mathrm{msrC}_{-} 3 \\
\mathrm{msrC}_{-} 4\end{array}$ & $\begin{array}{l}\text { AAGGAATCCTTCTCTCTCCG } \\
\text { GTAAACAAAATCGTTCCCG }\end{array}$ & 52 & 343 & $\begin{array}{l}\text { Werner, Hildebrandt } \\
\quad \& \text { Witte (2001) }\end{array}$ \\
\hline \multicolumn{5}{|l|}{ Gelatinase } \\
\hline $\begin{array}{l}\text { gelE_TE9 } \\
\text { gelE_TE10 }\end{array}$ & $\begin{array}{l}\text { ACCCCGTATCATTGGTTT } \\
\text { ACGCATTGCTTTTCCATC }\end{array}$ & 50 & 419 & Eaton \& Gasson (2001) \\
\hline Cytolysin & & & & \\
\hline
\end{tabular}




\begin{tabular}{ccccc} 
cylA_TE17 & TGGATGATAGTGATAGGAAGT & \multirow{2}{*}{59} & Eaton \& Gasson (2001) \\
cylA_TE18 & TCTACAGTAAATCTTTCGTCA & & & \\
Adhesion & & & & \\
ace1_F & AAAGTAGAATTAGATCCACAC & 59 & 320 & Mannu et al. (2003) \\
ace2_R & TCTATCACATTCGGTTGCG & & \\
Biofilm & TTACCAAGATGGTTCTGTAGGCAC & 60 & 913 & Shankar et al. (1999) \\
ESP46 & CCAAGTATACTTAGCATCTTTTG & & & \\
ESP47 & AAGAAAAAGAAGTAGACCAAC & & & \\
Aggregation & AAACGGCAAGACAAGTAAATA & 60 & 1553 & Eaton \& Gasson (2001) \\
agg_TE3 & & &
\end{tabular}




\section{Table 2 (on next page)}

Distribution of Enterococcus sp. isolated from fecal samples of Heliconius erato phyllis caterpillars. 
1

2

3

4

\section{Table 2:}

Distribution of Enterococcus sp. isolated from fecal samples of Heliconius erato phyllis caterpillars.

\begin{tabular}{lcccc}
\hline \multirow{2}{*}{ Species } & \multicolumn{4}{c}{ Number $(\%)$ of enterococci strains isolated of caterpillars from $\mathbf{1}$} \\
\cline { 2 - 5 } & HEAB2 & HEV2 & HES2 & Total (\%) \\
\hline E. faecalis & $2(2.04)$ & 0 & 0 & $\mathbf{2}(\mathbf{1 . 1 2})$ \\
E. casseliflavus & $83(84.69)$ & $42(65.62)$ & $7(43.75)$ & $\mathbf{1 3 2}(\mathbf{7 4 . 1 5 )}$ \\
E. mundtii & $13(13.26)$ & $19(29.68)$ & $6(37.50)$ & $\mathbf{3 8}(\mathbf{2 1 . 3 4 )}$ \\
Enterococcus sp. & 0 & $3(4.68)$ & $3(18.75)$ & $\mathbf{6 ( 3 . 3 7 )}$ \\
\hline Total & $\mathbf{9 8 ( 1 0 0 )}$ & $\mathbf{6 4}(\mathbf{1 0 0})$ & $\mathbf{1 6}(\mathbf{1 0 0 )}$ & $\mathbf{1 7 8 ( 1 0 0 )}$ \\
\hline 'HEAB2, female from Águas Belas; HEV2, female from Viamão; HES2, female from São Francisco de \\
Paula.
\end{tabular}




\section{Table 3(on next page)}

Antibiotic resistance profiles in enterococci isolated from fecal samples of Heliconius erato phyllis caterpillars 
Table 3:

Antibiotic resistance profiles in enterococci isolated from fecal samples of Heliconius erato phyllis cateipillars.

\begin{tabular}{|c|c|c|c|c|c|c|c|c|}
\hline \multirow{2}{*}{ Female $^{1}$} & \multirow{2}{*}{ Species (n) } & \multicolumn{4}{|c|}{ Number $(\%)$ of resistant strains ${ }^{2}$} & \multicolumn{3}{|c|}{ Profiles $^{3}$} \\
\hline & & ERY & CIP & NOR & RIF & SR & DR & MDR \\
\hline \multirow[t]{3}{*}{ HEAB2 } & E. faecalis (2) & $2(100)$ & 0 & 0 & $2(100)$ & 0 & $2(100)$ & 0 \\
\hline & E. casseliflavus (83) & $25(30)$ & $4(5)$ & $8(10)$ & $70(84)$ & $48(58)$ & $21(25)$ & $5(6)$ \\
\hline & E. mundtii (13) & 0 & 0 & 0 & 0 & 0 & 0 & 0 \\
\hline \multirow[t]{3}{*}{ HEV2 } & E. casseliflavus (42) & $27(64)$ & 0 & 0 & $23(55)$ & $28(67)$ & $11(26)$ & 0 \\
\hline & E. mundtii (19) & 0 & 0 & 0 & 0 & 0 & 0 & 0 \\
\hline & Enterococcus sp. (3) & 0 & 0 & 0 & $3(100)$ & $3(100)$ & 0 & 0 \\
\hline \multirow[t]{4}{*}{ HES2 } & E. casseliflavus (7) & 0 & 0 & 0 & 0 & 0 & 0 & 0 \\
\hline & E. mundtii (6) & 0 & 0 & 0 & 0 & 0 & 0 & 0 \\
\hline & Enterococcus sp. (3) & $1(33)$ & $1(33)$ & 0 & $2(67)$ & $1(33)$ & 0 & $1(33)$ \\
\hline & Total (178) & $55(31)$ & $5(3)$ & $8(4)$ & $100(56)$ & $80(45)$ & 34 (19) & $6(3)$ \\
\hline
\end{tabular}

${ }^{1}$ HEA\$32, female from Águas Belas; HEV2, female from Viamão; HES2, female from São Francisco de Paula. ${ }^{2}$ Antibiotics: ERY, erythr5mycin; CIP, ciprofloxacin; NOR, norfloxacin; RIF, rifampicin. ${ }^{3}$ Profiles: SR, single resistant; DR, double resistant; MDR, multiffug resistant. 